\title{
NEW SMALL-DIAMETER CFRP MATERIAL FOR FLEXURAL STRENGTHENING OF STEEL BRIDGE GIRDERS
}

\author{
Salar Tabrizi ${ }^{1}$, Hamid Kazem ${ }^{1}$, Sami Rizkalla ${ }^{1 *}$, Akira Kobayashi ${ }^{2}$ \\ ${ }^{1}$ Department of Civil, Construction and Environmental Engineering, North Carolina State University, \\ Raleigh, USA \\ ${ }^{2}$ Nippon Steel \& Sumikin Material Co., Ltd, Composites Company, Japan \\ ${ }^{*}$ Corresponding author. E-mail addresses: sami_rizkalla@ncsu.edu, \\ Phone: 919.513.1733, Fax: 919.513.1765
}

\section{ABSTRACT:}

This paper presents the research findings of an experimental program undertaken to examine the effectiveness of using small-diameter CFRP strands to increase the flexural capacity of steel beams and bridge girders. The experimental program included scaled steel-concrete composite beams, strengthened with these small-diameter strands. The CFRP strands were stitched together with a gap between the strands to allow the adhesive to penetrate and cover the entire perimeter of each strand. Results showed that the proposed system eliminated failure due to de-bonding of the strengthening materials and significantly increased the flexural capacity and stiffness of steel beams.

Keywords: small-diameter CFRP strands, steel, flexure, strengthening

\section{Introduction}

Due to the appealing benefits of Fiber Reinforced Polymer (FRP) materials, their use for strengthening of concrete structures and bridges has gained wide acceptance worldwide and became a common practice. This is mainly attributed to availability of FRP materials with higher elastic modulus relative to concrete and the extensive research conducted in the field during the last two decades which led to the development of the design guidelines and several international codes [1].

The use of FRP for steel structures has not been very successful in the past due to the low elastic modulus of FRP relative to steel. Recent production of Carbon FRP material with a similar or higher 
modulus than the elastic modulus of steel offers a promising alternative for flexural strengthening of steel structures and bridges. Most of bridge design codes require designing for higher vehicular live loads in comparison to that used in the initial design of existing bridges. Accordingly, existing bridges, even without any signs of distress, may require flexural strengthening to meet the current design standards.

Currently, flexural strengthening systems for steel structures consist of welding or bolting steel plates and/or bars as reinforcement for steel members. However, heavy weight of steel plates, high cost of construction in addition to being receptive to corrosion are serious disadvantage of this strengthening method. These problems encouraged researches to explore other alternatives [2]. Several researches explored the use of Fiber Reinforced Polymer (FRP) materials due to their well-recognized advantages including high strength to weight ratio and resistance to corrosion. The use of FRP for strengthening concrete structures has become well established technique and documented in several national and international codes. However, few researches explored the use of FRP materials for strengthening steel structures [3].

Recently, numbers of researches have explored the use of CFRP materials for flexural strengthening of steel members and structures. Majority of the research are focused on rehabilitation of naturally or artificially deteriorated steel beams. Miller et al. (2001) [4] examined the strengthening of steel beams using low elastic modulus CFRP. Shaat \& Fam (2008) [5], Kim \& Brunell (2011) [6], and Galal et al. (2012) [7] presented the results of experimental and analytical studies on the repair of artificially damaged steel beams using adhesively bonded CFRP sheets. Deng \& Lee (2007) [8] and Linghoff et al. (2010) [9] investigated the effectiveness of CFRP strengthening systems, by retrofitting undamaged steel beams. Furthermore, flexural strengthening of steel-concrete girders using high modulus CFRP laminates, investigated by Schnerch et al. (2007) [10], showed clearly that the governing mode of failure was debonding of the CFRP laminates. The low bonding capacity of the CFRP laminate was attributed to the fact that the laminates were bonded to the substrate from one face only. In a research program conducted by Al-Saidy et al. (2007) [11], three steel-concrete composite beams were strengthened using two elastic modulus CFRP materials and test results indicated significant increase in the ultimate flexural capacity. Tavakkolizadeh \& Saadatmanesh (2003) [12], El-Hacha \& Ragab (2006) [13], and Schnerch \& Rizkalla 
(2008) [14] studied the behavior of steel-concrete composite girders strengthened with high-modulus CFRP materials. Research findings indicated that the use of high-modulus CFRP significantly increased both the ultimate flexural capacity and the stiffness of the steel-concrete girders.

4 The recent development of small-diameter CFRP strands, shown in Figure 1, introduced a promising 5 alternative for strengthening steel structures (Hidekuma et al. (2011) [15], Hidekuma et al. (2012) [16], 6 Jiao et al. (2014) [17]). The CFRP strands are approximately $1.0 \mathrm{~mm}$ (1/25 in.) in diameter and are 7 stitched together leaving a gap between the strands. The gap between the strands allows the adhesive 8 material to penetrate and cover the entire perimeter of each strand, resulting in a better bond mechanism 9 in comparison to the use of laminates which are bonded to the substrate from one face only. The new 10 CFRP strands are produced with a wide range of elastic modulus equal or higher than that of steel.

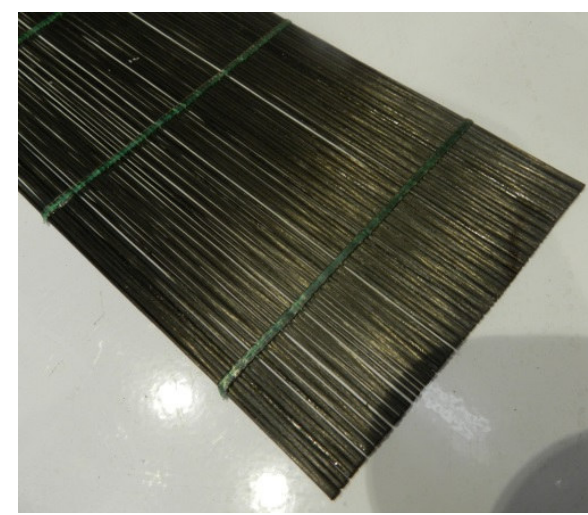

Figure 1: Small-diameter CFRP strand sheet

This paper summarizes an experimental program which investigates the use of these small-diameter CFRP strands for flexural strengthening of steel structures and bridges. The program included scaled steel-concrete composite beams strengthened at the tension flange of the steel beams to increase the flexural capacity. The parameters considered in the experimental program were the type of CFRP, reinforcing ratio and type of loading. The two types of CFRP materials that were examined for strengthening are low-modulus (LM) and intermediate-modulus (IM) CFRP material. The three types of loading investigated were static, cyclic and fatigue loadings. Test results of static loading were used to determine the most effective strengthening system and the selected system was tested under fatigue and cyclic loading. 


\section{Material Properties}

2 The mechanical and bond properties of the two types of CFRP strands used for flexural strengthening

3 were determined using two test methods. The first method was used to determine the tensile strength and

4 the elastic modulus of the two types of CFRP strands in accordance to ASTM D3039 [18] and Test

5 Method L2 of ACl 440.3R-04 [1]. Test results are summarized in Figure 2 for the two CFRP materials

6 used in the experimental program.

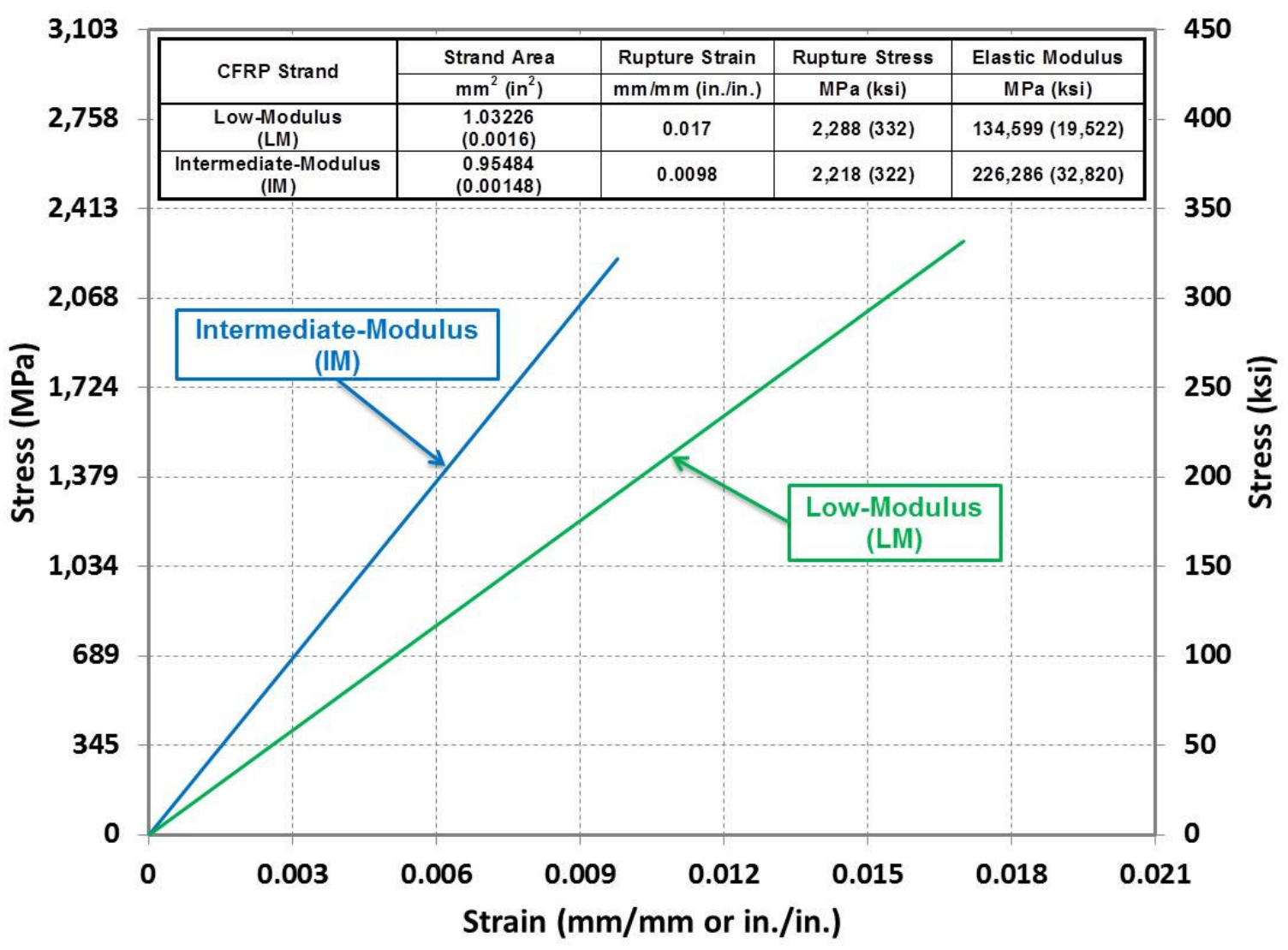

7

Figure 2: Mechanical properties of the two CFRP strands used for flexural strengthening

The second method of testing was used to evaluate the development length of the CFRP strands using six double strap joints as shown in Figure 3. One layer of CFRP strands was bonded on each side of the two steel plates, as sketched in in Figure 3, and the specimens were subjected to tension using MTS machine. The measured ultimate loads versus the variable bonded lengths for the double strap joints are 

is approximately $280 \mathrm{~mm}$ (11 in.).

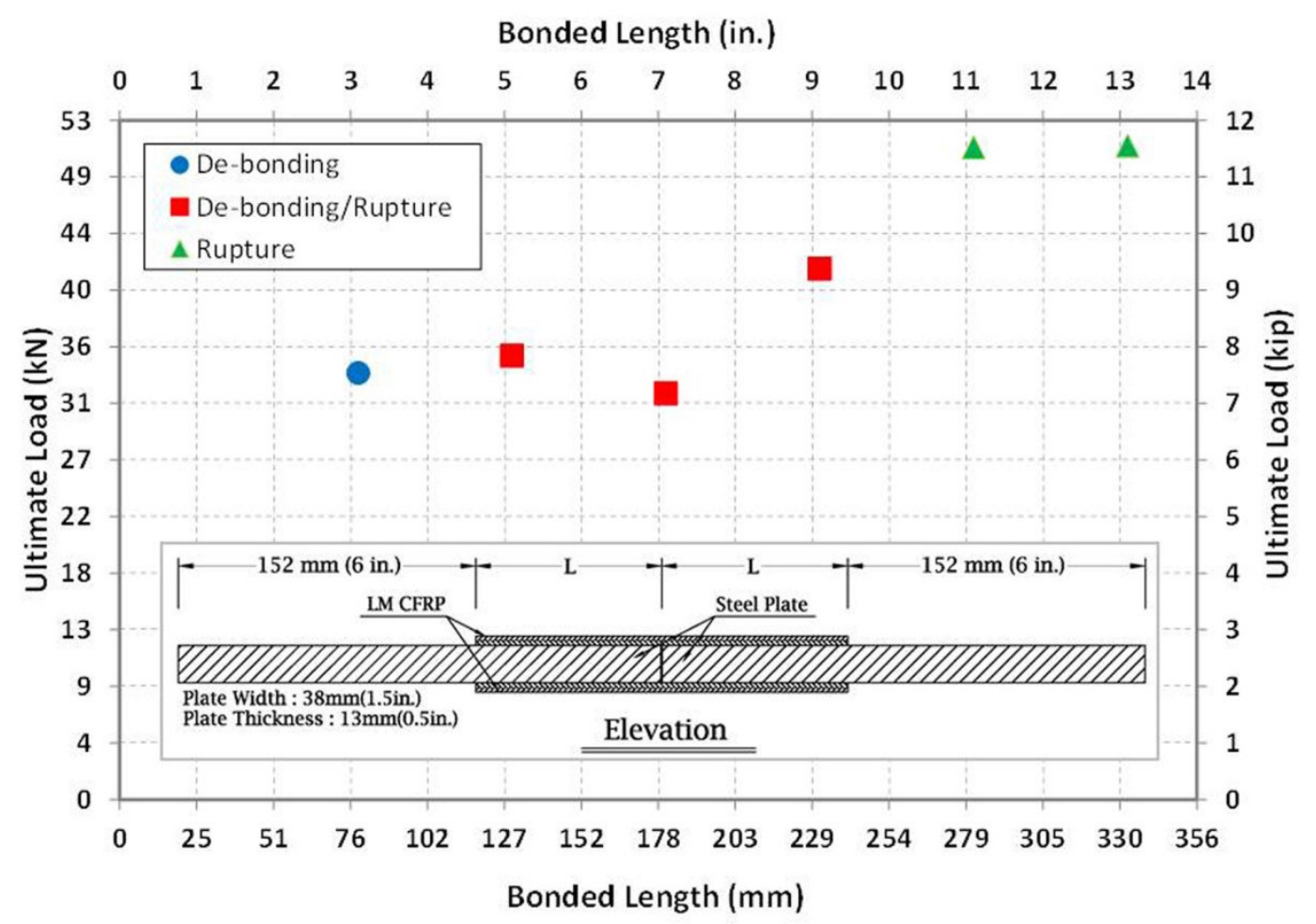

\section{3. Flexural Test Specimens}

Figure 3: Ultimate load vs the bonded length of the double strap joints

A total of eight scaled steel-concrete composite beams were tested in this study. Six beams were tested under static loading, one beam was tested under incremental cyclic loading and one beam was tested under fatigue loading. All of the test beams were $3350 \mathrm{~mm}(11 \mathrm{ft})$ long and were tested in a simply supported configuration as shown in Figure 4. The loads were applied using four-point bending configuration with a clear span of $3050 \mathrm{~mm}(10 \mathrm{ft})$. The applied two point loads were $610 \mathrm{~mm}(2 \mathrm{ft})$ apart at mid span. The steel beam was W-shape beam (W8x13), acting in composite action with a $533 \times 66 \mathrm{~mm}$ (21x2.6 in.) reinforced concrete slab using shear studs on top flange of the steel beam as shown in Figure

5. Stiffeners were welded at the location of the applied loads and at the two supports to prevent possible local buckling of the steel beam. All of the specimens were braced laterally at the supports and at the quarter span in order to prevent possible lateral buckling. All of the specimens were tested under 

minute before yielding and $2.54 \mathrm{~mm}(0.1 \mathrm{in}$.) per minute after yielding of the bottom flange of the steel beam.

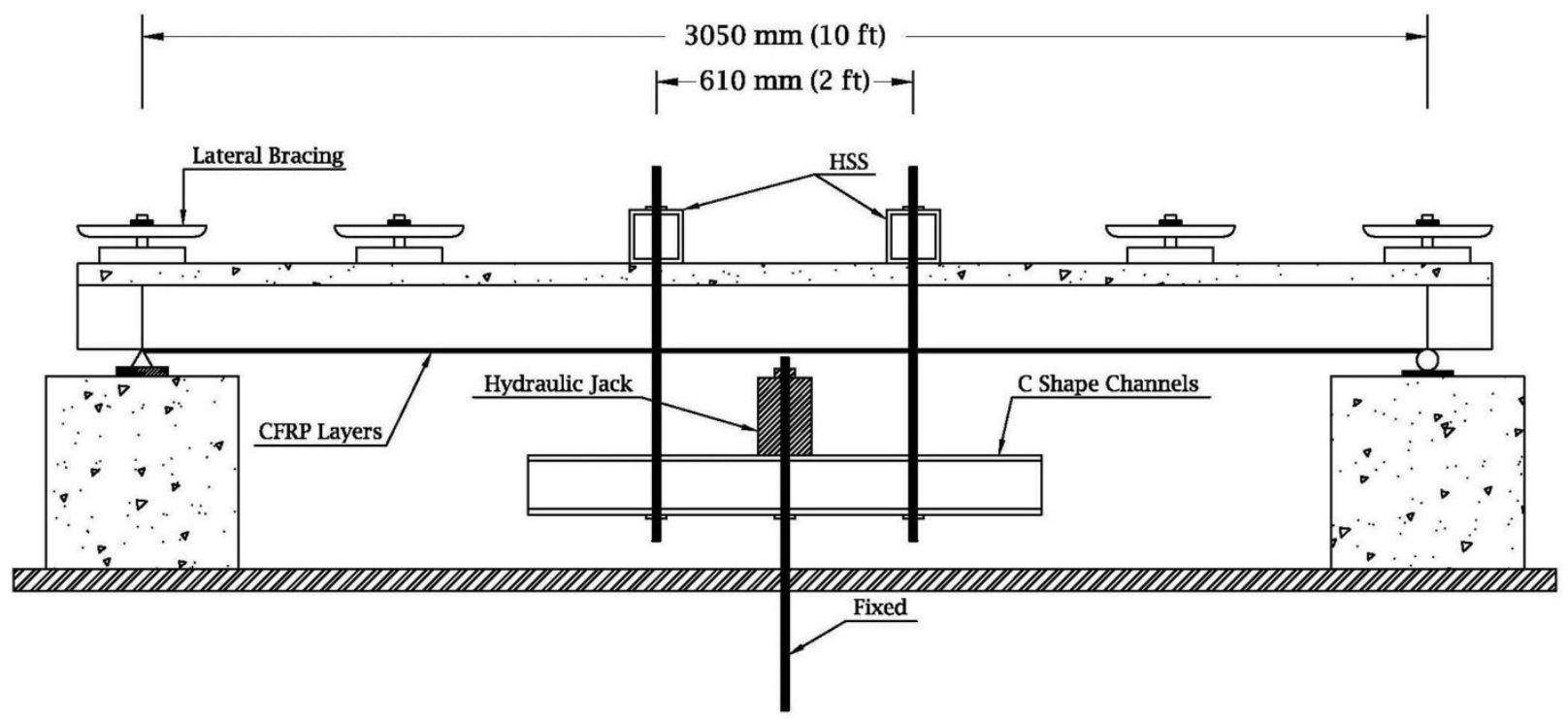

6 The test matrix of static tests is given in Table 1. The static tests included one un-strengthened beam

7 (S0-C) used as a control specimen, one beam strengthened with three layers of LM CFRP strands (S3LM) and one beam strengthened with four layers of LM CFRP strands (S4-LM). Also, one beam was strengthened with three layers of IM CFRP strands (S3-IM) and one beam was strengthened with four layers of IM CFRP strands (S4-IM). The CFRP strands were externally bonded to the bottom face of the lower steel flange as shown in Figure 5(a). The sixth beam was strengthened with a combination of both types of CFRP strands. Three layers of LM CFRP strands were bonded to the bottom face of lower flange and 2 layers of IM strands were bonded to the top face of the lower flange and the web, as shown in

14 Figure 5(b). Application of the CFRP strands was conducted using an overhead configuration to simulate field working conditions. Different types of instrumentation including strain gauges, pi gauges and string potentiometers were used to measure the induced strain at different locations along the span and the deflection in the mid-span. The deflection in the mid-span was determined using the average of two measurements of the string potentiometers. Locations of the strain gauges (SG) and the pi gauges (PI) 
with respect to the beam cross-section are shown in Figure 5. Typical fatigue test beam is shown in Figure 6. Two concrete blocks were used at the ends to ensure stability of the test setup.

\begin{tabular}{|c|c|c|c|c|c|c|c|}
\hline \multicolumn{2}{|c|}{ Specimen ID } & S0-C & S3-LM & S4-LM & S3-IM & S4-IM & S4-LM-IM \\
\hline LM CFRP & \multirow{2}{*}{ Number of Layers } & - & 3 & 4 & - & - & 3 \\
\cline { 3 - 8 } & - & - & - & 3 & 4 & 2 \\
\hline IM CFRP & & & &
\end{tabular}

5

6

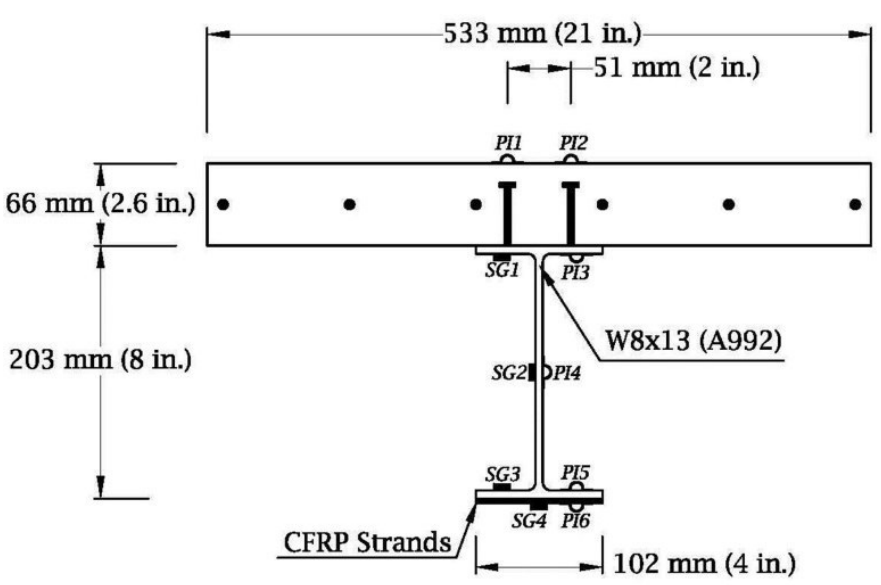

(a)

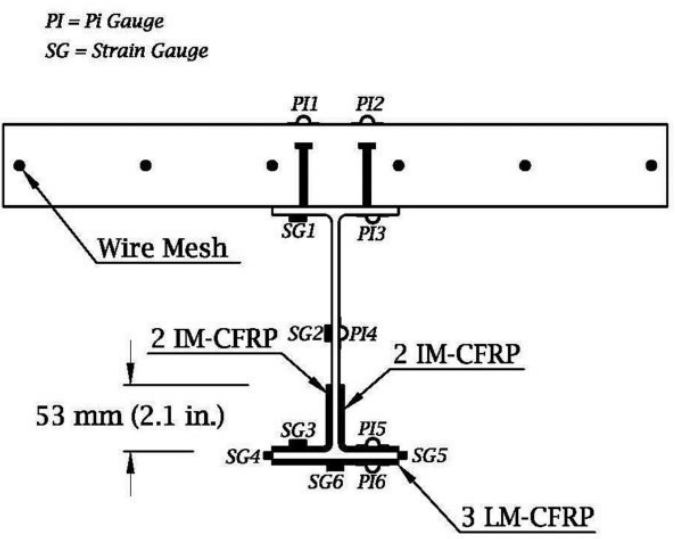

(b)

Figure 5: Cross section details of the static test specimens, a) Specimens S3-LM, S4-LM, S3-IM, S4-IM, b) Specimen S4-LM-IM

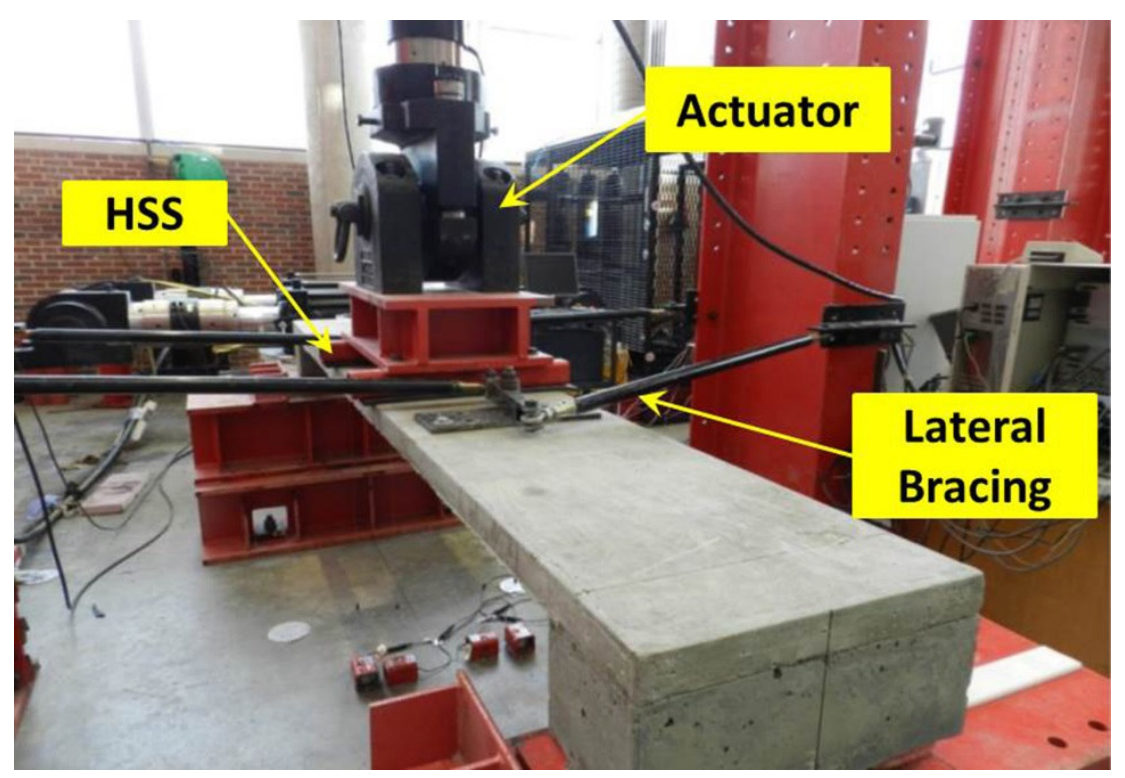

Figure 6: Fatigue specimen test setup 


\subsection{Behavior under Static Loading}

The results of the six beams tested under static loading conditions are given in Table 2. The measured loads at failure and percentage increases of the load carrying capacity in comparison to the control beam are given. The measured loads at the initiation of steel yielding and their percentage increases to the control beam are also given. The pre-yielding and post-yielding stiffness, measured by the slope of the load-deflection response, and their percentage increases are presented. The displacement ductility was evaluated based on the measured ratio of displacement at failure to displacement at the onset of yielding.

Table 2: Test results summary of the tested specimens under static loading

\begin{tabular}{|c|c|c|c|c|c|c|c|c|}
\hline \multirow{2}{*}{$\begin{array}{l}\text { Specimen } \\
\text { ID }\end{array}$} & \multicolumn{2}{|c|}{$\begin{array}{c}\text { Measured } \\
\text { Load } \\
\text { at Failure }\left(F_{u}\right) \\
\end{array}$} & \multicolumn{2}{|c|}{$\begin{array}{c}\text { Measured } \\
\text { Yield } \\
\text { Load }\left(F_{y}\right)\end{array}$} & \multicolumn{2}{|c|}{$\begin{array}{c}\text { Pre-Yield } \\
\text { Stiffness } \\
\left.\text { (El }\left.\right|_{\text {Pre-Yield }}\right) \\
\end{array}$} & \multirow{2}{*}{$\begin{array}{c}\text { Post-Yield } \\
\text { Stiffness } \\
\text { (El } \text { Post-Yield }^{\text {Intease }} \\
\text { Increase } \\
(\%) \\
\end{array}$} & \multirow{2}{*}{$\begin{array}{c}\begin{array}{c}\text { Displacement } \\
\text { Ductility }\end{array} \\
\text { in./in. or } \\
\mathrm{mm} / \mathrm{mm}\end{array}$} \\
\hline & $\begin{array}{l}\mathrm{kN} \\
\text { (kip) }\end{array}$ & $\begin{array}{c}\text { Increase } \\
(\%)\end{array}$ & $\begin{array}{c}\text { kN } \\
\text { (kip) }\end{array}$ & $\begin{array}{c}\text { Increase } \\
(\%)\end{array}$ & $\begin{array}{l}\text { kN/mm } \\
\text { (kip/in.) }\end{array}$ & $\begin{array}{c}\text { Increase } \\
(\%)\end{array}$ & & \\
\hline SO-C & $\begin{array}{l}214 \\
(48)\end{array}$ & 1 , & $\begin{array}{c}133 \\
(30.00)\end{array}$ & 1,1 & $\begin{array}{c}11.7 \\
(66.70)\end{array}$ & 1. & $x_{1}$ & 4.87 \\
\hline S3-LM & $\begin{array}{l}311 \\
(70)\end{array}$ & 49 & $\begin{array}{c}167 \\
(37.50)\end{array}$ & 25.00 & $\begin{array}{c}13.2 \\
(75.45)\end{array}$ & 13.18 & 96 & 4.43 \\
\hline S4-LM & $\begin{array}{l}365 \\
(82) \\
\end{array}$ & 71 & $\begin{array}{c}173 \\
(39.00) \\
\end{array}$ & 30.00 & $\begin{array}{c}13.2 \\
(75.50)\end{array}$ & 13.23 & 183 & 4.06 \\
\hline S3-IM & $\begin{array}{l}329 \\
(74)\end{array}$ & 54 & $\begin{array}{c}169 \\
(38.00)\end{array}$ & 26.67 & $\begin{array}{c}15.3 \\
(87.40)\end{array}$ & 31.10 & 228 & 3.50 \\
\hline S4-IM & $\begin{array}{l}358 \\
(81) \\
\end{array}$ & 67 & $\begin{array}{c}185 \\
(41.50) \\
\end{array}$ & 38.33 & $\begin{array}{c}15.9 \\
(90.60) \\
\end{array}$ & 35.90 & 236 & 3.45 \\
\hline S4-LM-IM & $\begin{array}{l}379 \\
(78)\end{array}$ & 78 & $\begin{array}{c}182 \\
(41.00) \\
\end{array}$ & 36.67 & $\begin{array}{c}13.8 \\
(78.80) \\
\end{array}$ & 18.20 & 242 & 3.56 \\
\hline
\end{tabular}

Measured load-deflection at mid-span for all tested specimens is shown in Figure 7. Test results show that using CFRP strengthening system increases the stiffness within the elastic range and significantly increases the ultimate flexural capacity. Test specimen S4-LM-IM, with combined LM and IM CFRP strands, achieved the highest increase of the flexural capacity in comparison to the other specimens due to the use of five layers and different layup. The increase in the ultimate flexural capacity was 78 percent in comparison to the control specimen. The flexural strength of S4-LM beam increased up to 71 percent. Test results indicated that for the same number of CFRP layers, IM CFRP could be more effective in increasing the pre-yield and post-yield stiffness. However, their use may reduce the overall displacement ductility due to the limited rupture strain in comparison to the LM CFRP. Test results indicated in general 

that the use of the small-diameter CFRP strand strengthening system is effective in increasing the 2 yielding and ultimate load carrying capacity of steel members.

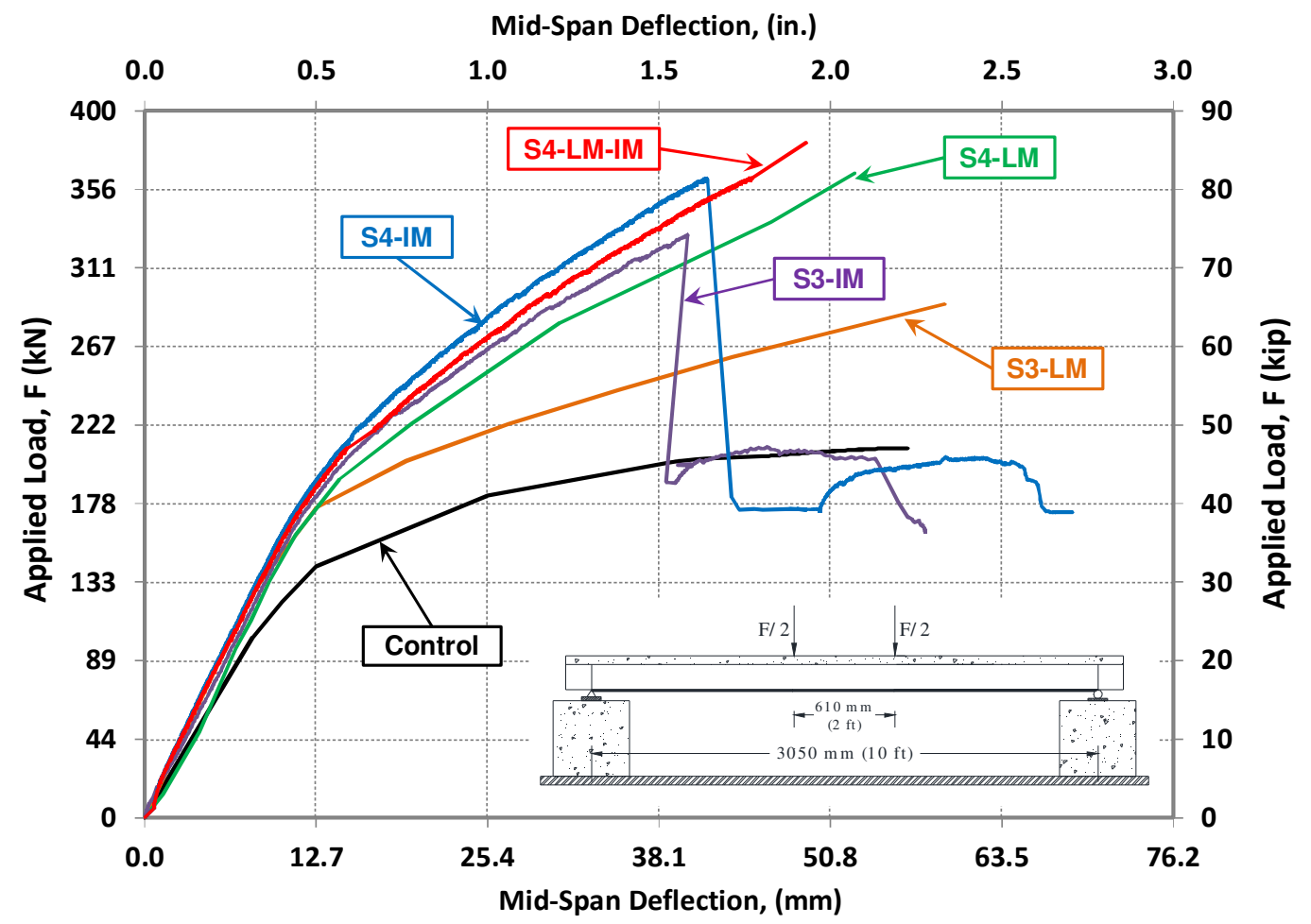

Figure 7: Applied load vs. mid-span deflection of tested specimens under static loading

\section{$5 \quad 4.2$ Shear Lag Phenomena}

6 The measured load-strain of the steel at the bottom flange and the CFRP strands are shown in Figure 8.

7 The behavior indicates that measured strains of the steel and CFRP for the beams strengthened with LM

8 CFRP strands were the same until very late stage of yielding as shown in Figure 8(a). The specimens

9 strengthened with IM CFRP strands reflect formation of some shear lag behavior after yielding as shown

10 in Figure 8(b) for specimens S3-IM, S4-IM. The shear-lag mainly reflects the difference of elastic modulus 11 of CFRP and steel after yielding. 


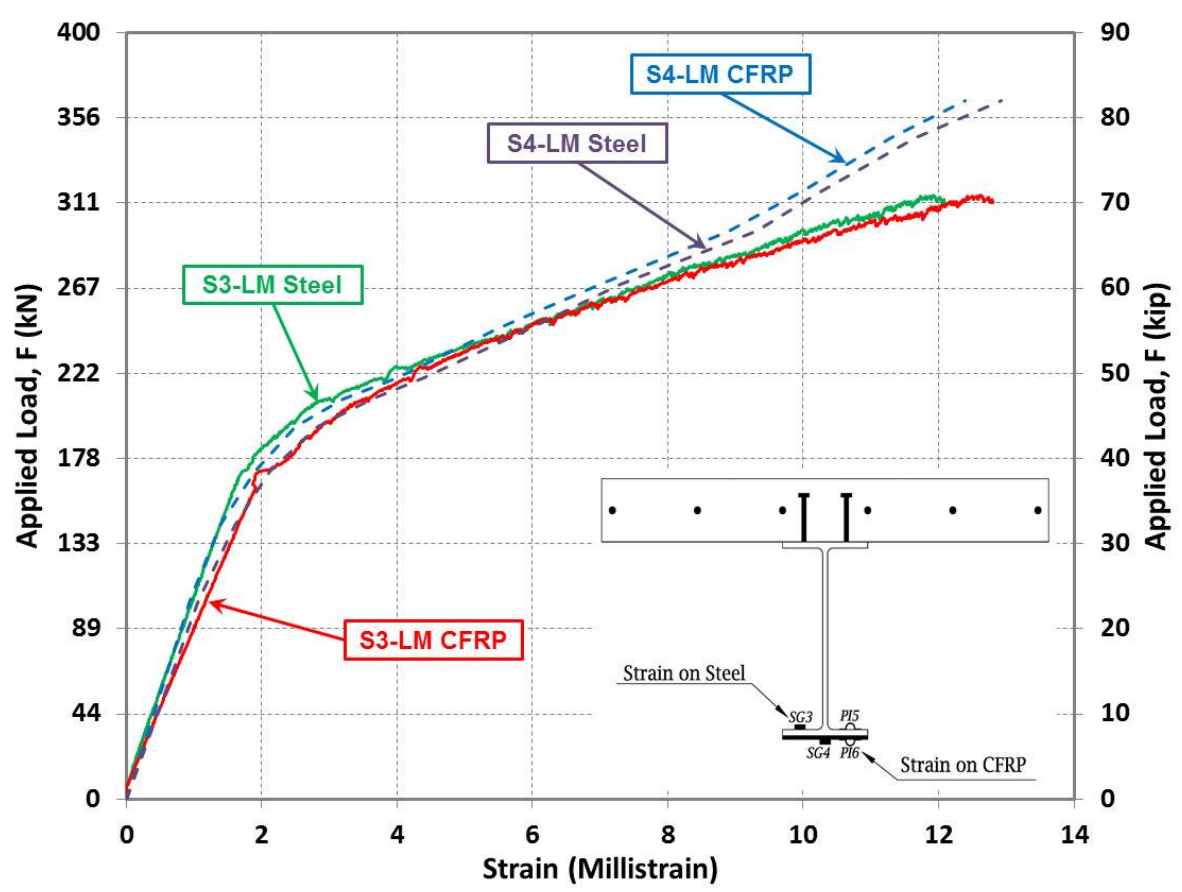

(a)

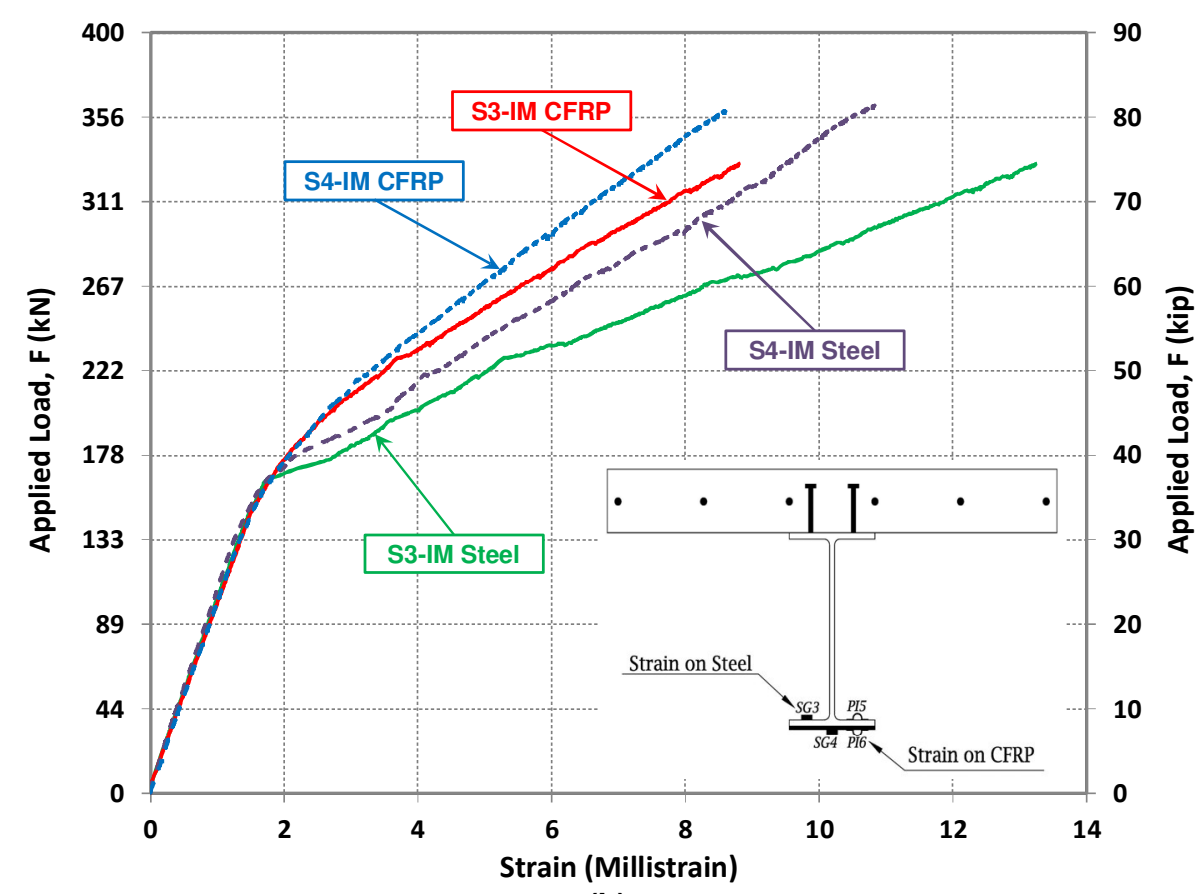

(b)

Figure 8: Applied load vs. longitudinal strain of the steel bottom flange and the CFRP strands of a) S3-LM \& S4-LM, b) S3-IM \& S4-IM

7 The measured strain profiles of the test specimens at failure are shown in Figure 9. The strain profiles of

8 specimens S3-LM \& S4-LM exhibit linear behavior across the entire section after yielding. The strains in 9 the CFRP strands were compatible to the strain of steel at bottom flange. The strain profiles of S3-IM \& 
S4-IM exhibit some shear lag behavior evident by the difference of the measured strain at the bottom

2 surfaces of the steel flange and the CFRP strands. As noted, this behavior obviously reflects the result of

3 the significant difference between the stiffness of the steel and the IM CFRP strands after yielding of the 4 steel.

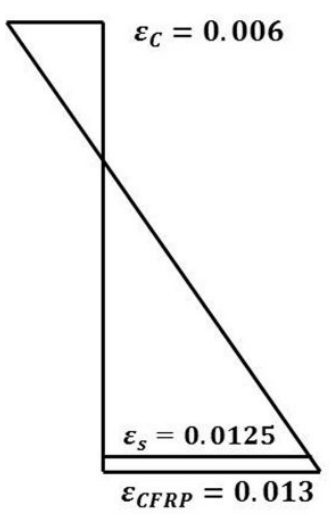

(a)

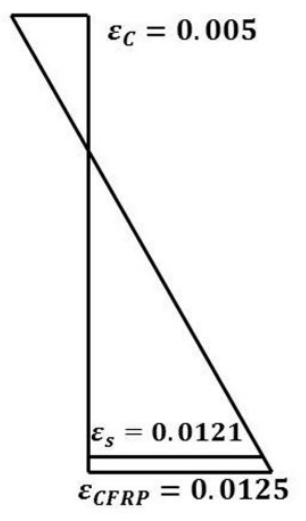

(b)

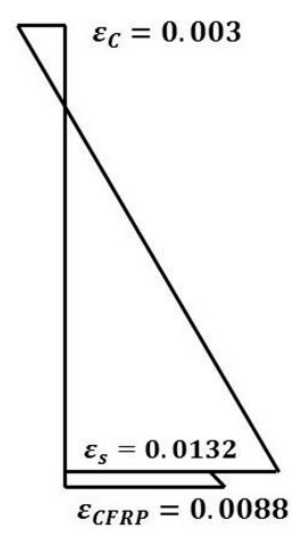

(c)

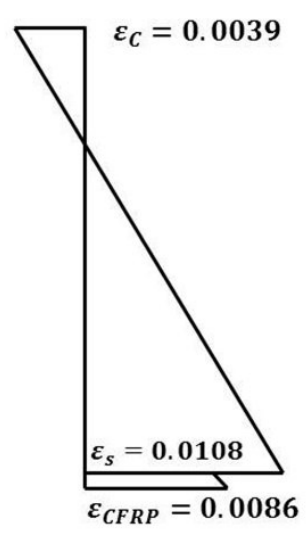

(d)

Figure 9: Measured strain profile of a)S3-LM, b)S4-LM, c)S3-IM, d)S4-IM

\section{$7 \quad 4.3 \quad$ Effectiveness of the strengthening system}

8 Effectiveness of the strengthening system was evaluated as the ratio of the measured strain at failure to 9 the rupture strain of the CFRP strands obtained from material testing. The measured average 10 effectiveness of the LM CFRP strand was 80 percent of the rupture strain since the failure was due to 11 crushing of the concrete in the compression zone. Failure of the beams strengthened with IM CFRP 12 strands was due to rupture of the strands indicating that IM CFRP strands were fully utilized. Test results 13 also indicate that increasing the reinforcement ratio of the strengthening system may reduce the 14 effectiveness of the material utilization and the overall displacement ductility.

15 Test results did not exhibit any de-bonding of the CFRP strands under static loading condition. This 16 behavior confirms the ability of the adhesive to penetrate through the gap between the strands to cover 17 the entire perimeter of each strand providing an excellent bonding mechanism. 


\subsection{Failure Modes}

2 The observed failure mode for all tested specimens strengthened with the LM CFRP strands was due to crushing of the concrete which is considered to be the most favorable failure mode for steel-concrete composite structures. The observed failure mode for specimens strengthened with the IM CFRP material was rupture of the CFRP strands due to the limited rupture strain of the IM CFRP strands. After rupture of the CFRP strands, the beam was capable to carry load equal to the capacity of the un-strengthened steel-concrete composite beam and the final failure occurred due to crushing of the concrete at the top zone of the concrete slab. The observed two modes of failure are shown in Figure 10.

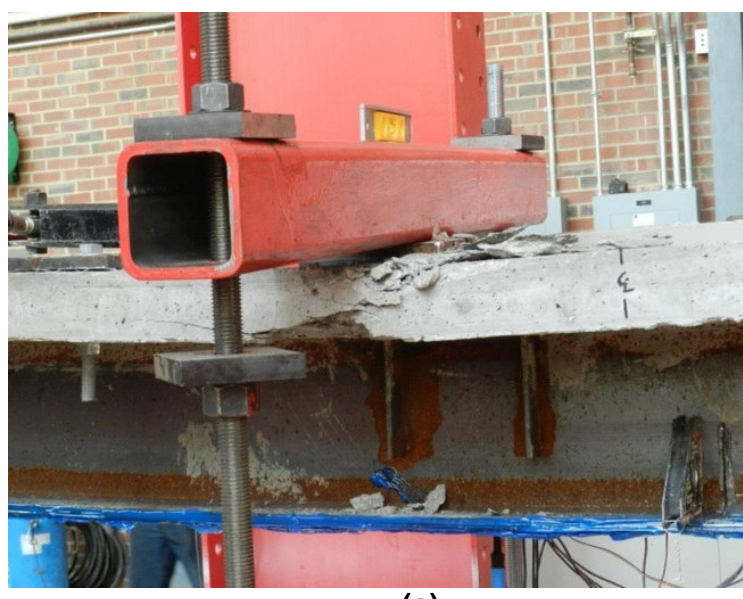

(a)

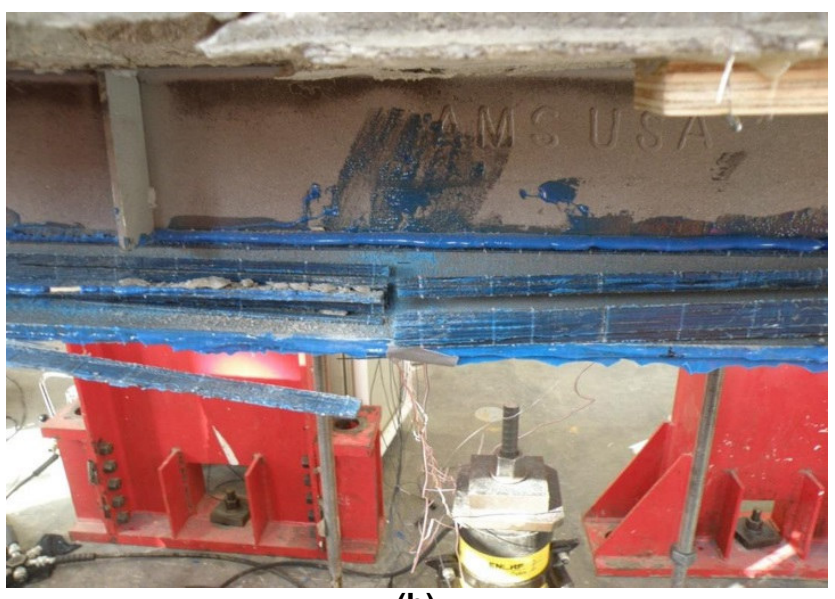

(b)

Figure 10: Failure modes a) Crushing of the concrete slab for S4-LM, b) Rupture of the IM CFRP strands for S4-LM-IM

Based on the behavior and the observed mode of failure of the six beams tested under static loading, it is recommended to use the LM CFRP strands for flexural strengthening of steel structures. The system can increase the yielding load, increase the ultimate flexural capacity, minimize the reduction of displacement ductility and achieve desirable mode of failure. The following sections study the behavior of the recommended system under the effect of cyclic and fatigue loading conditions.

\subsection{Behavior under Cyclic Loading}

A new specimen, S4-LM-C, strengthened with four layers of LM CFRP strands was used to study the behavior of the proposed strengthening system under cyclic loading. The cyclic loading was applied in 
increments of 10 percent of the measured ultimate flexural strength from the static tests. The load at each level was cycled three times up-to-failure. The load-deflection behavior of specimen S4-LM-C is compared to specimen S4-LM tested under static loading and is shown in Figure 11. Test results confirm that both specimens have approximately the same behavior and ultimate flexural capacity. The slight decrease in the capacity of the specimen subjected to the cyclic load may be attributed to the effect of cyclic loading on the concrete slab in the compression zone and/or the different concrete properties of two different batches used for casting the two specimens. Measured strain of the LM CFRP strands indicates similar degree of utilization of the material and confirms that they did not de-bond under cyclic loading conditions. Test results confirmed that the selected strengthening system is also effective for cyclic loading conditions.

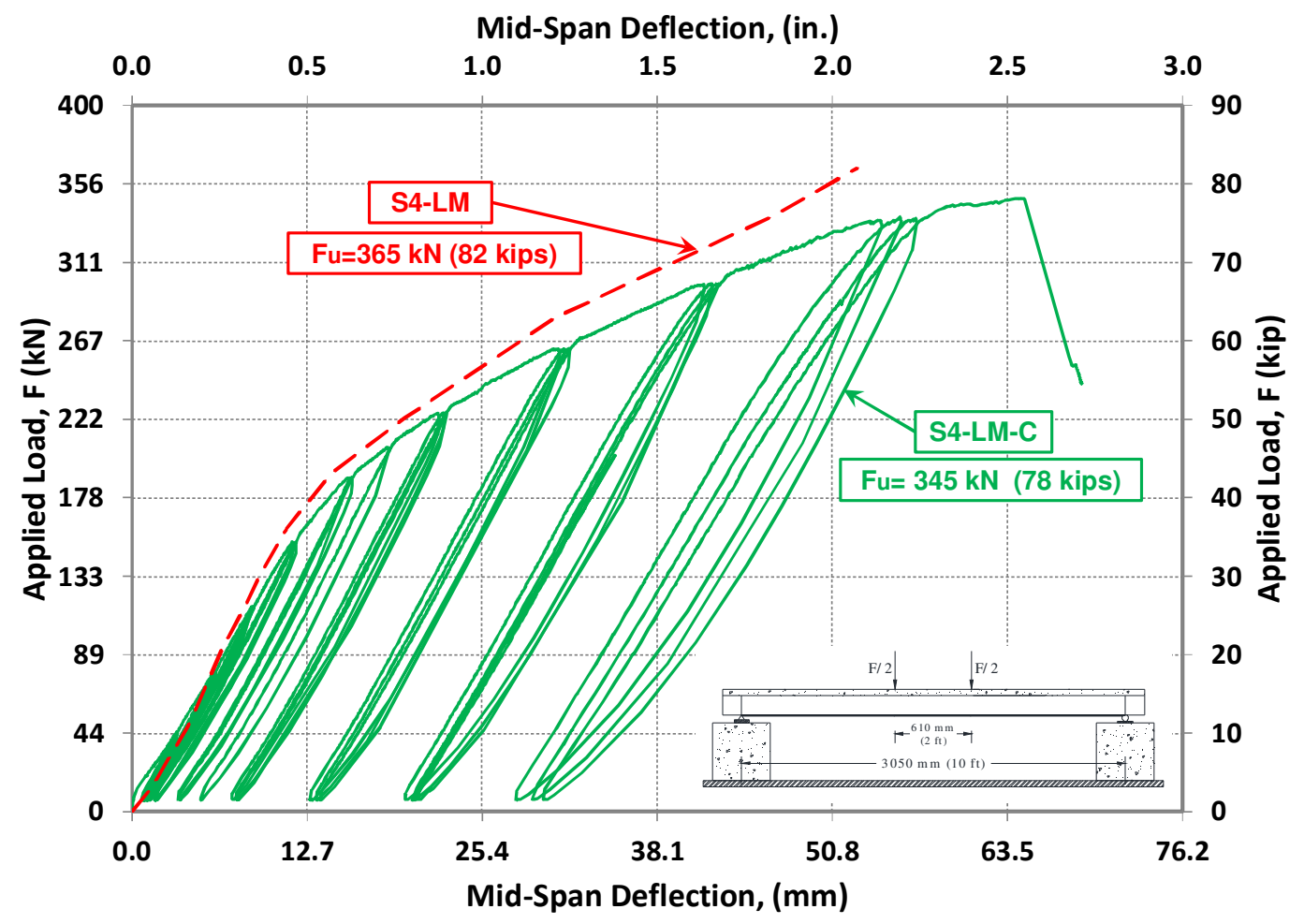

Figure 11: Applied load vs. mid-span deflection of S4-LM-C under cyclic load and S4-LM under static load

\subsection{Behavior under Fatigue Loading}

The fatigue test specimen was loaded with a frequency of $1.55 \mathrm{~Hz}$. The minimum fatigue load was $35 \mathrm{kN}$ (7.8 kips) which is 10 percent of the ultimate load. The maximum fatigue load was $129 \mathrm{kN}$ (29 kips) which 
1 is equivalent to minimum of the yield strength of the un-strengthened beam, and 80 percent of the yield

2 strength of the strengthened beam measured from the static test. The specimen was loaded to two million

3 cycles and then loaded statically to failure using the same test setup. The load-deflection behavior of

4 specimen, S4-LM-F, strengthened by four layers of LM CFRP strands and subjected to fatigue loading is

5 shown in Figure 12. The load-deflection behavior was similar to the behavior of the specimen S4-LM

6 tested under static loading. After completion of the fatigue loading, the specimen was tested statically up-

7 to-failure.

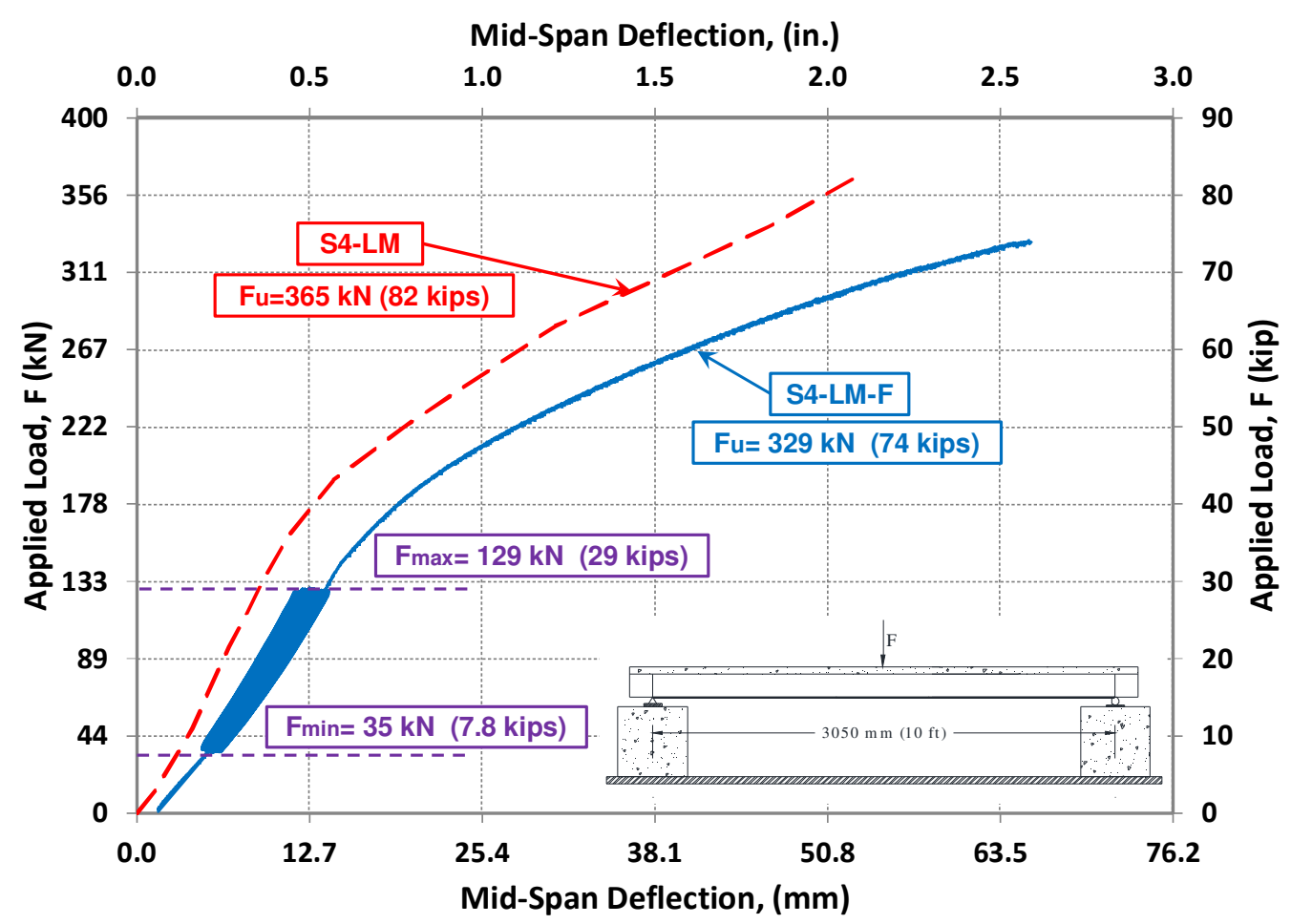

8

Figure 12: Applied load vs. mid-span deflection of S4-LM-C under fatigue load and S4-LM under static load

The ultimate capacity was only 15 percent less than the similar specimen tested under static loading. The difference may be attributed to the fatigue creep behavior of the concrete in the compression zone and/or the difference in the concrete batches used for the two individual specimens. It should be noted that some longitudinal cracks were observed in the concrete during testing due to the nature of point load application which was distributed along the width of the slab. In addition, no de-bonding was observed at 
failure load. Test results confirm that the selected strengthening system is also effective to carry fatigue

2 loading.

3

4

\section{Summary \& Conclusion}

This paper presents a new strengthening system for steel structures and bridges. The proposed system introduces the use of new small-diameter carbon fiber reinforced polymer, CFRP, strands which are believed to have quite an advantage in comparison to current strengthening scheme using CFRP sheets or laminates. The research findings are based on an experimental program conducted to investigate the effectiveness of the new system. The strengthening program comprised of testing eight scaled steelconcrete composite beams. Beams were strengthened using two types of CFRP strands as low-modulus (LM) and intermediate-modulus (IM) with different reinforcement ratios. The behavior was examined under static, cyclic and fatigue loading conditions. Test results indicate that the small-diameter CFRP strands are effective, similar to the use of sheets and laminates, in increasing the flexural capacity and stiffness with the important advantage of total elimination of any possible de-bonding of the strengthening material. Similar to the currently used CFRP material types, the proposed system indicated excellent performance under the three loading conditions. The research findings may be summarized as follows:

a) The proposed strengthening system for steel structures and bridges using small-diameter CFRP strands can totally eliminate de-bonding failure of the strengthening materials which could occur by using laminate CFRP materials. Preventing the de-bonding was achieved due to the total coverage of the small-diameter strands by the epoxy adhesive instead of one side as it is the case for laminates.

b) Using LM CFRP strands does not affect displacement ductility of the system and failure typically occurs due to crushing of the concrete in the compressive zone which is a favorable mode of failure.

c) IM CFRP strands can be effectively used in cases where strengthening is required to reduce deflection of the flexural members. Nevertheless, use of a reinforcement ratio higher than the balanced reinforcement ratio will allow failure to be controlled by crushing of the concrete in the compressive zone. 
d) Use of IM CFRP material may cause shear lag due to the significant difference of its elastic modulus to the elastic modulus of the steel after yield.

e) Use of CFRP strengthening systems delays yielding of steel to higher load levels.

f) The proposed strengthening system is effective for cyclic and fatigue loadings conditions.

\section{6. Acknowledgments}

6 The authors would like to acknowledge Nippon Steel \& Sumikin Material Co., Ltd, Composites Company, 7 Japan and the National Science Foundation (NSF) Center of Integration of Composites into Infrastructure $8(\mathrm{CICl})$, NCSU for their financial support. Thanks are also due to the staff of the Constructed Facilities 9 Laboratory (CFL), NCSU for their help throughout the experimental program.

\section{References}

[1] $\mathrm{ACl}$ 440.3R-04, "Guide test methods for fiber-reinforced polymers (FRPs) for reinforcing or strengthening concrete structures," ACI Committee 440, 2004.

[2] S. F. Tarbrizi, "CFRP Strengthening of Steel Structures," M.Sc. Thesis, North Carolina State University., 2013.

[3] A. Shaat and A. Fam, "Axial loading tests on short and long hollow structural steel columns retrofitted using carbon fiber reinforced polymers," Canadian Journal of Civil Engineering, vol. 33, p. 458-470, 2006.

[4] T. C. Miller, M. J. Chajes, D. R. Mertz and J. N. Hastings, "Strengthening of steel bridge girder using CFRP plates," Journal of Bridge Engineering, vol. 6, pp. 514-522, 2001.

[5] A. Shaat and A. Fam, "Repair of Cracked Steel Girders Connected to Concrete Slabs Using Carbon-Fiber-Reinforced Polymer Sheets," Journal of Composites for Construction, vol. 12, pp. 650-659, 2008.

[6] Y. J. Kim and G. Brunell, "Interaction between CFRP-repair and initial damage of wide-flange steel beams subjected to three-point bending," Composite Structures, vol. 93, pp. 1986-1996, 2011.

[7] K. Galal, H. M. Seif EIDin and L. Tirca, "Flexural performance of steel girders retrofitted using 
CFRP materials," Journal of Composites for Construction, vol. 16, pp. 265-276, 2012.

[8] J. Deng and M. M. Lee, "Behaviour under static loading of metallic beams reinforced with a bonded CFRP plate," Composite Structures, vol. 78, pp. 232-242, 2007.

[9] D. Linghoff, M. Al-Emrani and R. Kliger, "Performance of steel beams strengthened with CFRP laminate - Part 1: Laboratory tests," Composites: Part B, vol. 41, pp. 509-515, 2010.

[10] D. Schnerch, M. Dawood, S. Rizkalla and E. Sumner, "Proposed design guidelines for strengthening of steel bridges with FRP materials," Construction and Building Materials, vol. 21, pp. 1001-1010, 2007.

[11] A. H. Al-Saidy, F. W. Klaiber and T. J. Wipf, "Strengthening of steel-concrete composite girders using carbon fiber reinforced polymer plates," Construction and Building Materials, vol. 21, pp. 295302, 2007.

[12] M. Tavakkolizadeh and $H$. Saadatmanesh, "Strengthening of steel-concrete composite girders using carbon fiber reinforced polymers sheets," Journal of Structural Engineering, vol. 129, pp. 3040, 2003.

[13] R. El-Hacha and N. Ragab, "Flexural strengthening of composite steel-concrete girders using advanced composite materials," in Third International Conference on FRP Composites in Civil Engineering (CICE 2006), Miami, Florida, USA, 2006.

[14] D. Schnerch and S. H. Rizkalla, "Flexural strengthening of steel bridges with high modulus CFRP strips," Journal of Bridge Engineering, vol. 13, pp. 192-201, 2008.

[15] Y. Hidekuma, A. Kobayashi, T. Miyashita and M. Nagai, "Reinforcing effect of CFRP strand sheets on steel members," Journal of Physical Science and Application, vol. 1, pp.155-162, 2011.

[16] Y. Hidekuma, A. Kobayashi, Y. Okuyama, T. Miyashita and M. Nagai, "Experimental study on debonding behavior of CFRP for axial tensile reinforced steel plate by cfrp strand sheets," in The Third Asia-Pacific Conference on FRP in Structures (APFIS 2012), Hokkaido University, Sapporo, Japan, 2012.

[17] H. Jiao, H.B. Phan and X.L. Zhao, "Fatigue behaviour of steel elements strengthened with strand 
CFRP sheets," Advances in Structural Engineering, vol. 17, No. 12, pp. 1719-1727, 2014.

[18] ASTM D3039/D3039M-08, "Standard test method for tensile properties of polymer matrix composite materials," ASTM International, 2008. 